\title{
Las leyendas en las clases de español como lengua extranjera: una propuesta a partir del enfoque por tareas
}

\begin{abstract}
Por: Eliana Dias Laurido', Instituto Federal de Educación, Ciencia y Tecnología de Roraima, Brasil, y Nathália Oliveira da Silva Menezes², Instituto Federal de Educación, Ciencia y Tecnología de Roraima, Brasil. Recibido: $\quad 14$ de marzo, 2017. Aprobado: 21 de mayo, 2017
\end{abstract}

\section{Resumen}

Este artículo presenta una propuesta didáctico-pedagógica para desarrollar actividades con base en la literatura de la frontera entre Brasil y Venezuela, específicamente leyendas, mediante el enfoque por tareas para la enseñanza de español como lengua extranjera (LE) en la carrera de Licenciatura en Letras -Español y Literatura Hispánica- del Instituto Federal de Educación, Ciencia y Tecnología de Roraima (IFRR), en Brasil. La propuesta planteada se origina de una inquietud de los profesores de español/LE de desarrollar un aprendizaje significativo y eficaz, la cual pretende que los estudiantes sean capaces de ejecutar actividades para ampliar el conocimiento de las destrezas de la lengua meta. El aporte metodológico del artículo consiste en una investigación cualitativa, bajo orientaciones de la investigación-acción con criterios observacionales y narrativos. Los resultados obtenidos apuntan que el enfoque por tareas puede facilitar el proceso de enseñanza y aprendizaje de los estudiantes, así como propiciar un aprendizaje más autónomo. Otra conclusión observada fue que el uso de las leyendas en clases de español despierta el interés, la participación y la creatividad de los estudiantes, de modo que proporciona un ambiente favorable para el desarrollo de la enseñanza y para el aprendizaje de español como lengua extranjera.

\section{Abstract LEGENDS IN SPANISH AS A FOREIGN LANGUAGE CLASSES:
A PROPOSAL BASED ON A TASK APPROACH}

This article presents a pedagogical-didactic proposal which has as an objective develop activities based on the literature of the Brazilian-Venezuelan border, specifically legends, through a task-based approach for the teaching of Spanish as a foreign language (LE) in the licenciatura program in Arts, Spanish and Hispanic Literature (IFRR), in Brazil. The proposal herein presented has its origin in the curiosity some teachers of Spanish/ LE have as to develop meaningful and efficient learning. Thus in the herein research underlies the task-based approach, since it intends students to be able to carry out activities which provide a wider variety of knowledge of the skills of the target language. The methodological contribution of this article consists of a qualitative study under the orientations of critical research, both observational and narrative. The obtained results in the building up of tasks support the notion that the task-based approach facilitates the teachinglearning process of students, as well as a more autonomous learning. Another conclusion was that the use of legends in Spanish classes awakens the interest, participation and creativity of students, providing an environment favorable for the teaching and learning of Spanish as a foreign language.

1 Eliana Dias Laurido es licenciada en Letras por la Universidad Federal de Roraima, Brasil. También es Magister en Enseñanza del Español como Lengua Extranjera por la Universidad Antonio de Nebrija, Madrid, España y doctoranda en Lingüística Aplicada al Español como Lengua Extranjera, también de la Universidad Antonio de Nebrija, España. Actualmente es profesora el Instituto Federal de Roraima, Brasil. Contacto: eliana.laurido@gmail.com.

2 Nathália Oliveira da Silva Menezes es licenciada en Letras -Español y Literatura Hispánica- por el Instituto Federal de Roraima-IFRR. También es licenciada en Psicología, por la Universidad Cathedral en Brasil, especialista en Psicopedagogía Institucional por la Universidad Montenegro, Brasil y Magister en Letras por la Universidad Federal de Roraima- UFRR, Brasil. Actualmente es profesora en el Instituto Federal de Roraima- IFRR. Contacto: nnathalia.oliveira@gmail.com.
Eliana Dias Laurido y Nathália Oliveira da Silva Menezes. Las leyendas en las clases de Español como Lengua Extranjera: una propuesta a partir del enfoque por tareas. Revista Comunicación. Año 38, volumen 26, número 1, enero - junio, 2017. Instituto Tecnológico de Costa Rica. ISSN: 0379-3974 / e-ISSN:1659-3820

\section{PALABRAS CLAVE:}

leyenda, enseñanza de idiomas, método de enseñanza, aprendizaje de adultos, trabajos prácticos, español.

\section{KEY WORDS:}

legend, teaching of languages, teaching method, adult learning, practical work, Spanish. 


\section{INTRODUCCIÓN}

Planear clases de español como lengua extranjera exige una serie de decisiones por parte del profesor, en cuanto a la metodología adoptada, el enfoque utilizado y el material didáctico elegido, entre otras cuestiones surgidas en el momento de organizar sus clases. Así pues, este artículo tiene como objetivo último plasmar una propuesta de desarrollo de actividades de español como lengua extranjera en un curso de formación de profesores, mediante el enfoque por tareas, teniendo por eje las leyendas de la frontera de Brasil y Venezuela.

Según Cascudo (2006), la leyenda es un elemento de fijación que determina un valor local, explica un hábito que puede ser semejante en varias partes del mundo, pero con particularidades del lugar donde ocurre. Sin la existencia de un documento histórico para garantizar su veracidad, los pueblos resucitan el pasado y lo cuentan por medio de las leyendas.

A partir de esta definición, se optó por trabajar con las leyendas, pues de esta manera los estudiantes se acercan a este género textual que rescata la cultura y tradición de un pueblo. Específicamente, esta propuesta trata sobre las leyendas de Brasil y de Venezuela, pues son parte del contexto real del estudiante que las autoras tratan, y así es posible ver reflejadas las semejanzas y diferencias lingüísticas, culturales y sociales entre esos países.

El aporte metodológico de la investigación está orientado por la investigación cualitativa, caracterizada por Chizzotti (2003) como un campo transdiciplinar que involucra conocimientos de las ciencias humanas y sociales para estudiar determinado fenómeno. Triviños (2012) por su parte, aclara que en la investigación cualitativa, el investigador posee amplia libertad teórica y metodológica para realizar sus estudios, siempre y cuando siga las condiciones de exigencia de un trabajo científico.

Este estudio también fue desarrollado bajo la investigación acción, con criterios observacionales y narrativos. Para Stenhouse (1998) en la investigación - acción, los investigadores realizan un movimiento sustantivo que permite concretar un sentido y un significado, en un área específica de la acción, y lo hacen adquiriendo la concienciación de la perspectiva del aprendizaje de los alumnos, además de buscar beneficiar a otros que no pertenezcan al grupo investigado.
Los estudios narrativos "utilizan la observación naturalista en el entorno natural de la conducta investigada (...) con métodos antropológicos de recogida de datos como las notas de campo, los diarios, o las grabaciones de audio o video" (McKernan, 1999, p. 80). Para el mismo autor, la observación participante "se emplea cuando el investigador desea comprender implicándose en el rol de las personas que estudia." (p. 80).

La propuesta aquí planteada fue aplicada a un grupo de diecisiete estudiantes del cuarto módulo (con el nivel B1 del Marco Común Europeo) del Curso de Licenciatura en Letras -Español y Literatura Hispánica- del Instituto Federal de Educación, Ciencia y Tecnología de Roraima en Brasil. Estos estudiantes son brasileños, con edades entre los 18 y los 45 años. Para analizar los datos, se utilizó la observación, grabaciones en vídeo de las clases ministradas y registro de las tareas desarrolladas.

Para sostener teóricamente el trabajo se eligió el enfoque por tareas, un método de enseñanza-aprendizaje originado a partir de la corriente comunicativa. Inicialmente fue creado para desarrollar el proceso de enseñanza-aprendizaje de lenguas, pero dado su eficiencia, no es difícil deducir que también puede ser aplicado en cualquier otra asignatura.

De acuerdo con Estaire (2007), en el enfoque por tareas las clases necesitan estar organizadas en secuencia de tareas cuidadosamente pensadas. Cada una de esas tareas debe girar alrededor de un tema y conducir de forma coherente a la elaboración de una tarea final. De esta manera, el enfoque por tareas parte de una premisa más global (las tareas por realizar), para después decidir las funciones, puntos gramaticales o vocabulario por enseñar.

Para comprender cómo funciona el enfoque por tareas en la práctica, es necesario definir el concepto de tareas que subyace este enfoque. De una manera general, la tarea es cualquier actividad realizable en un tiempo determinado. Todos los días se realizan tareas, desde las más simples como organizar las actividades domésticas, hasta las más complejas, como sería el diseño de las partes de un proyecto científico (López y Blanco, 2011).

Sin embargo, el concepto de tarea que fundamenta el enfoque aquí tratado, necesita ser sistematizado con un fin de aprendizaje del alumnado. Para López y Blanco (2011), las tareas son "Actividades 


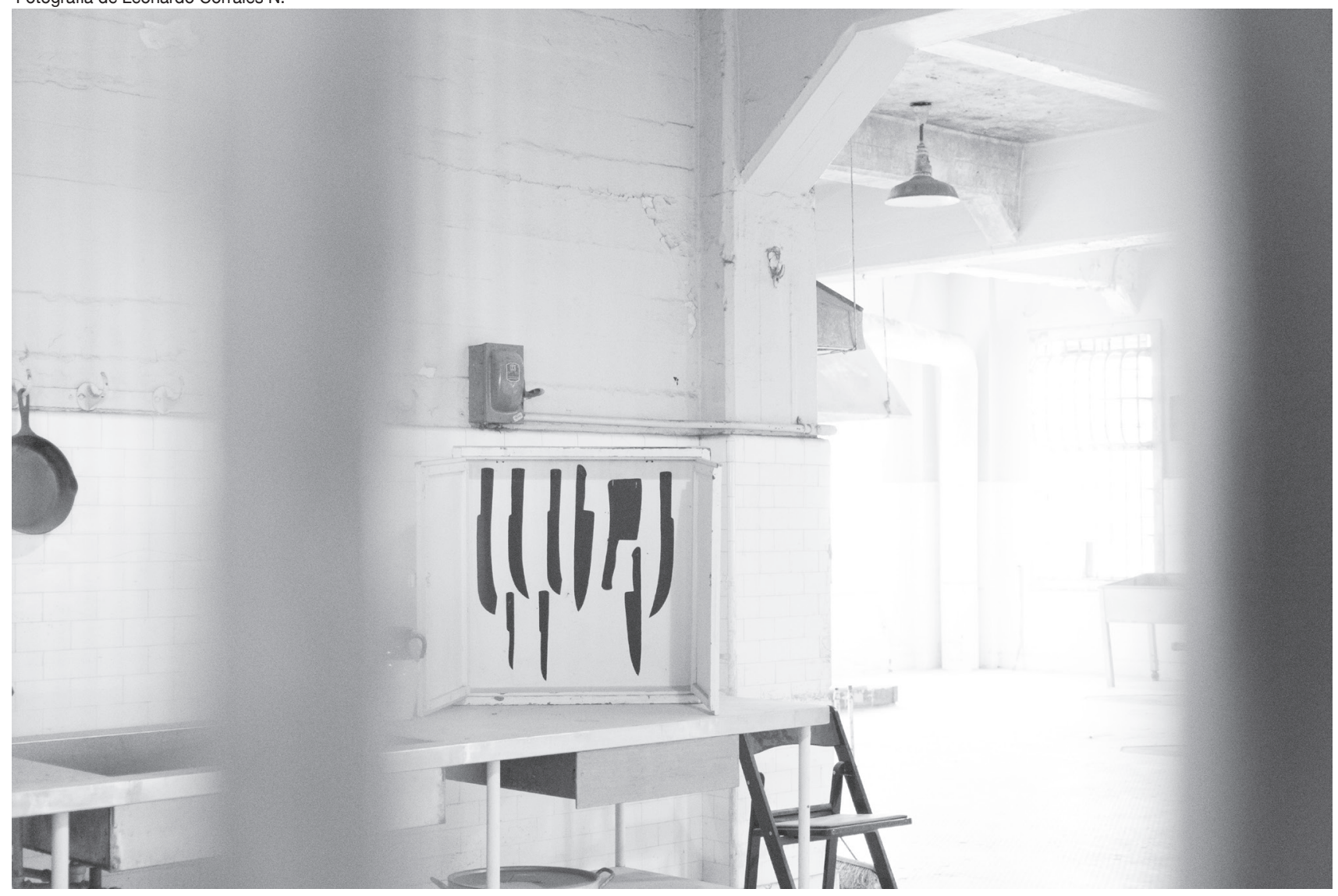

concretas, reales o verosímiles, acciones de la vida cotidiana - no solo académicas -, de interés para los alumnos, que se realizan en clase, o desde la clase, y que como ejes de la unidad didáctica, dinamizan los procesos de comunicación y de aprendizaje y llevan a aprender todo lo necesario para poder realizarlas en la nueva lengua" (López y Blanco, 2011, p. 7).

En vista de esto, las tareas colaboran con el aprendizaje de los estudiantes, además de tener una finalidad de aprendizaje en el salón de clase. Sánchez (2009), afirma que la tarea didáctica deriva y está hincada en el concepto de tarea en la vida real. En cuanto a la aplicación en la clase, este autor propone que una tarea necesita precisarse y adaptarse según el entorno de la clase. Además, debe poseer un fin específico que utilice la lengua objeto del aprendizaje.

Estaire (2007) por su parte, divide las tareas utilizadas en el aula en dos tipos: las tareas de comunicación y las tareas de apoyo lingüístico. Las primeras son unidades de trabajo en el aula centradas en el significado, no en aspectos formales de la lengua; implican a todos los alumnos en la comprensión o producción oral o escrita; tienen una finalidad comunicativa; reproducen procesos de comunicación, oral o escrita, de la vida cotidiana. Estas además, pueden ser evaluadas desde una perspectiva comunicativa o como instrumento de aprendizaje.

Por otro lado, las tareas de apoyo lingüístico se centran en los aspectos formales de la lengua. Muchas veces son la base de las tareas de comunicación, pues preparan a los alumnos desde el punto de vista lingüístico para la realización de las tareas de comunicación (Estaire, 2007).

Finalmente, Sánchez (2009) señala que las tareas propuestas en clase necesitan conllevar la aplicación de procedimientos para comunicarse con otras personas, usando la lengua objeto de estudios. Así, es posible organizar una secuencia de tareas que orienten a la ejecución de una tarea final que estará bien elaborada, pues influye en el resultado de la propuesta final. 
A continuación se presenta la contextualización de la propuesta didáctica aquí planteada, para que se comprenda el contexto sociocultural en que los sujetos de la investigación están insertos así como también, el material seleccionado para la enseñanza del español como lengua extranjera, mediante el enfoque por tareas.

\section{CONTEXTUALIZACIÓN DE LA PROPUESTA DIDÁCTICA: LAS LEYENDAS DE LA FRONTERA BRASIL Y VENEZUELA}

La propuesta de desarrollar actividades de español como lengua extranjera en un curso de formación de profesores, mediante el enfoque por tareas, tiene por eje las leyendas de la frontera Brasil-Venezuela. Para esta labor, se optó por trabajar con leyendas de los dos países por la cercanía tanto geográfica, lingüística y cultural. Esto le permite al estudiantado la posibilidad de expandir sus conocimientos acerca de las relaciones existentes entre los dos países.

La frontera Brasil-Venezuela está separada por 15 kilómetros de distancia. Del lado brasileño está la ciudad de Pacaraima, que está a 215 kilómetros de la capital Boa Vista (ciudad donde está ubicado el IFRR). Del lado venezolano está la ciudad de San- ta Elena de Uairén. Para Rodrigues (2006), el flujo de personas entre las ciudades de Santa Elena de Uairén y Pacaraima es muy intenso y se realizan migraciones diarias y transfronterizas que posibilitan conexiones sociales, comerciales, laborales, de servicios, de parentesco, vecindad y religiosidad.

La realidad anteriormente mencionada está reflejada en el salón de clase de los estudiantes del curso de Licenciatura en Letras -Español y Literatura Hispánica-, pues esta es su cotidianidad.

Por las cuestiones planteadas, se propuso trabajar con leyendas, tanto brasileñas como venezolanas, para que los estudiantes puedan, además de conocer sobre las producciones literarias del país vecino, plantear reflexiones sobre las relaciones lingüísticas, culturales y sociales vivenciadas entre Brasil y Venezuela.

Así, fueron seleccionadas dos leyendas. La leyenda brasileña se Ilama "Iara". Cuenta la historia de una sirena que encantaba a los hombres por su belleza, los hechizaba y los llevaba hacia las aguas profundas. Por su parte, la leyenda venezolana trabajada fue "La Sayona" que trata del espíritu de una mujer que perseguía a los hombres traicioneros. A continuación se pueden leer ambas:

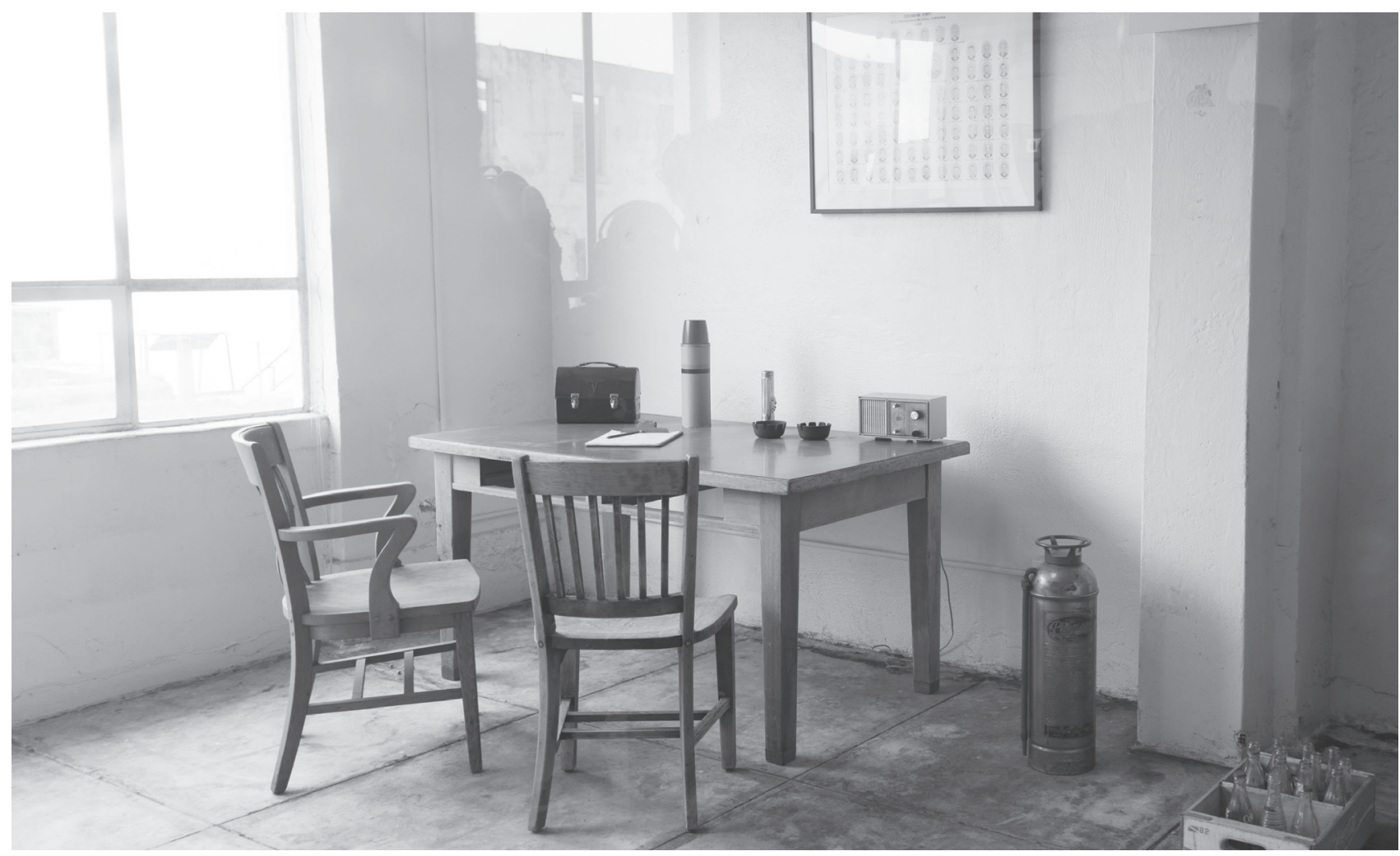

Fotografía de Leonardo Corrales N. 


\section{LEYENDA BRASILEÑA: IARA}

Los indígenas más primitivos y los habitantes del sertón creen en la existencia de una de las más bellas leyendas, que es la de lara, o más conocida como la fabulosa Madre del Agua, y que dicen los indios y los del sertón que se trata de una mujer lindísima de piel bastante clara, cabellos negros que le llegan hasta la cintura, senos opulentos y siempre se muestra desnuda de cintura para arriba; hacia abajo tiene la forma y la cola de un pez. Se parece a la leyenda de la sirena europea de aguas saladas, pero este es un ser encantado que vive en lagos, en los ríos y sobre las ramas cerradas de las flores del riachuelo.

Los indios y los del sertón coinciden en afirmar que todo aquel que ve a la tal lara se queda inmediatamente atraído por su belleza y hermosura y acaban siendo arrastrados por ella por causa de su canto maravilloso al fondo de las turbias aguas. Por ese motivo tanto los indios como los del sertón no se lo ponen fácil y tienen mucho cuidado, apartándose de los lagos y los ríos; del mismo modo, tampoco pasan cerca de los riachuelos al caer la tarde. Ellos sienten verdadero pavor de los encantamientos de lara y de acabar dominados por su seductor canto angelical.

Se cuenta que, en los inicios de la civilización indígena, vivía en las orillas del río Amazonas, Jaraguari, el hijo de un gran cacique llamado Takaluté, de la tribu de los tuxuama. Era un apuesto muchacho, lindo como el sol, de piel bronceada y fuerte como un jabalí. Los otros indios lo envidiaban debido a su gran belleza y coraje. Su fuerza era descomunal y su destreza en el manejo del arco y la flecha era una cosa excepcional.

Las mujeres de la tribu siempre estaban a su alrededor, siendo el mejor partido para casarse con las mujeres de la comunidad, que soñaban casarse, pero solamente si fuese con Jaraguari. Ellas admiraban su musculatura, su gracia y su valentía. Los viejos también lo admiraban, pues Jaraguari los trataba con mucho cariño y respeto.

El bello y dorado Jaraguari, subía todas las tardes en su canoa hacia la punta del río Taruma, donde permanecía de forma silenciosa y solitaria durante muchas horas, quedándose allí hasta altas horas de la noche. Su vieja y sabia madre, impresionada con el cambio repentino del comportamiento de su valiente hijo guerrero, le preguntó:

- ¿Qué tipo de pesca es esa, hijo mío, que se prolonga hasta altas horas de la madrugada? ¿No tienes miedo de las terribles artimañas traicioneras de Anhangá? ¿Por qué estás ahora tan triste? ¿Dónde está la alegría que te animaba la vida?

El bello y obediente Jaraguari se quedó en silencio, con la mirada distante en dirección a su madre como si estuviese viendo una escena de cine que le venía a la mente en aquel momento de devaneo.

- ¡Madre, yo la vi, madre! Nadando entre las flores de los riachuelos. ¡Qué linda es! ¡Parece la luna de las noches claras! ¡Yo la vi, madre! Sus cabellos negros como el carbón con el brillo plateado de la luna, sus ojos negros como dos jaboticabas. ¡Su canto, ah! ¡Su canto era tan suave que parecía el mismo uirapuru al gorjear en medio del bosque! ¡Yo la vi, madre!

La vieja y sabia india, al escuchar las palabras de su hijo, abrió los ojos de par en par, se le erizaron los cabellos, sus carnes comenzaron a temblar internamente de pavor $y$, tras volver a la normalidad, y recuperarse del susto del relato de su hijo, la india berreaba, tirándose al suelo de tierra batida y gritando entre lágrimas:

— ¡Huye de esa mujer infernal, hijo mío, ella es la terrible lara o conocida como Madre del Agua. ¡Ella va a matarte! ¡Huye, huye, hijo mío!

El apuesto indio no dijo nada y salió de la aldea. Al día siguiente, al caer la tarde, su bella y maravillosa lara se deslizaba suavemente entre los riachuelos yendo en dirección hacia la punta del Taruma. Pero de repente, los indios que estaban pescando en sus orillas tuvieron una maravillosa visión amorosa. Fueron testimonio de una escena dantesca. Todos les gritaron a los que estaban más alejados:

- ¡Corran, corran amigos! ¡Vengan a ver una cosa extraña!

A lo lejos, casi al otro lado de la orilla del río, los indios avistaron la canoa del elegante Jaraguari, y abrazada al joven guerrero, todos pudieron ver aquella hermosa mujer medio pez, con sus cabellos largos y negros. Todos acabaron creyendo que el gran guerrero Jaraguari había sido seducido y encantado por la india lara. Desde aquel día, el respetado Jaraguari, no volvió nunca más a su aldea, para desesperación de sus familiares, especialmente de su vieja y sabia madre (Platero y Ehrichs, 2011, pp. 44-49). 


\section{LEYENDA VENEZOLANA: LA SAYONA}

Esta aparición materializada en la figura de una mujer delgada, alta, de uñas largas y muy elegante, es considerada como una señal castigadora y reprobatoria de la mala conducta e infidelidades cometidas por los hombres.

Esta leyenda originaria de Los Llanos, data de la época colonial; sin embargo, hoy en día, todavía se escuchan "cuentos" de personas asegurando que han sido interceptados en algún camino por esta gélida y espantosa mujer.

Un habitante de El Regalo, haciendo referencia a su encuentro con La Sayona, nos contó que una noche cuando su esposa dormía, se escapó para visitar a su amante. En medio de su caminata, se sorprendió al ver que dicha mujer venía a su encuentro, pero caminaba tambaleante y su cabello era muy largo.

El hombre empezó a correr detrás de ella, pero al Ilegar a la puerta de la casa en donde vivía la mujer, esta siguió de largo. El hombre extrañado:

"¡Pero bueno!, ¿qué pasa?"

Cuando volteó, se encontró con una mujer blanca y con los dientes como un hacha. El hombre salió corriendo y cuando llegó a la puerta de su casa, se encontró con la aparición nuevamente. Esta le extendió los brazos para estrecharlo, y así lo hizo.

Cuando el hombre logró soltarse, entró a su casa y oyó la voz de su comadre que le preguntaba:

"¿Compadre, y qué le pasó?, y este le contestó:

- ¡Qué buen susto comadre!, dígame, salí un momentico a orinar afuera y me salió esa mujer...

- "Mire compadre, esa es La Sayona".

- "¿No será que usted tiene cosas con otra mujer? Cuídese, yo que le digo...".

El hombre asegura que después de esta experiencia — aunque fue hace mucho tiempo—, nunca más le quedaron ganas de volver a serle infiel a su mujer...

Otras versiones dicen que la intención de La Sayona es atraer a los hombres hasta el cementerio, sin que estos puedan verle el rostro, con la intención de aterrorizarlos al descubrir que han estado caminando en compañía de una calavera.

La Sayona tiene la particularidad de "desdoblarse", esto quiere decir que puede presentarse como un perro, un lobo o como la mujer antes descrita.

Así que si eres uno de esos hombres, que disfrutas pensando que puedes tener varias mujeres, no te descuides, porque puede que un día de estos La Sayona decida hacerte una visita (La Sayona, 2009).

LA UTILIZACIÓN DE LEYENDAS EN CLASE DE ESPAÑOL: PROPUESTA A PARTIR DEL ENFOQUE POR TAREAS

La propuesta aquí presentada se basa en el marco para la programación de una unidad didáctica mediante tareas (Estaire y Zanón, 1990). Este modelo integra los diferentes ejes del proceso educativo: ob- jetivos, contenidos, metodología y evaluación, conforme la figura 1: 
Figura 1. Marco para la programación de una unidad didáctica mediante tareas

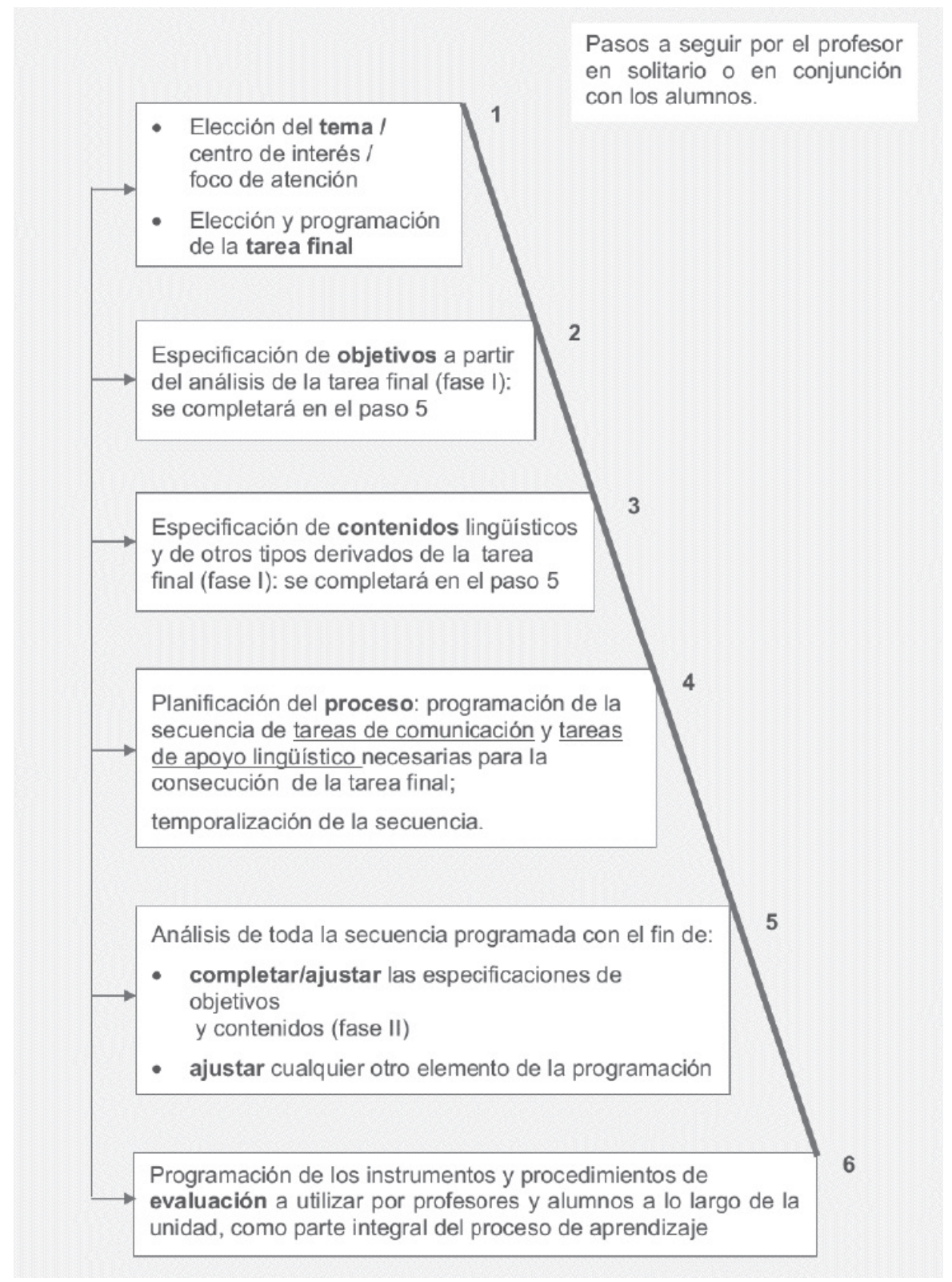

Fuente: Estaire y Zanón, 1990, p. 66.

A partir de los planteamientos del cuadro anterior, se propuso una secuencia didáctica mediante tareas, para trabajar las leyendas en las clases de español/ LE con un grupo de estudiantes del cuarto módulo del curso de "Letras español y literatura hispánica" del IFRR. Para mejor comprensión, se presentará la propuesta, paso a paso, siguiendo las orientaciones del "Marco para la programación de una unidad didáctica mediante tareas" de Estaire y Zanón (1990). Para Estaire (2007), las clases están organizadas como una secuencia de tareas cuidadosamente engarzadas alrededor de un tema que conduce de forma coherente a la elaboración de una tarea final. De esta manera, primeramente se pensó en la temática y luego en la tarea final. A partir de eso, se 
estructuró la secuencia de microtareas que orientaron la elaboración de la tarea final. La propuesta didáctica elaborada se explica a continuación.

\section{PROPUESTA DIDÁCTICA}

1.TEMA: Las leyendas en las clases de español como lengua extranjera.

2.OBJETIVO GENERAL: Desarrollar actividades de español como lengua extranjera, mediante el enfoque por tareas, teniendo por eje las leyendas de la frontera Brasil-Venezuela.

3.CONTENIDOS: Género textual: leyendas (específicamente "Leyenda de la Sayona" de Venezuela y "Leyenda de lara" de Brasil); descripción de las características físicas y psicológicas; adjetivos; verbos en presente de indicativo.

\section{SECUENCIA DE LAS MICROTAREAS PROPUESTAS}

Antes de aplicar la secuencia de microtareas propuesta, el profesor hace una introducción de la clase: explica el concepto de las leyendas, indaga si los estudiantes conocen las leyendas de Brasil y de Venezuela. Luego, divide la clase en grupos y empieza la secuencia de las microtareas por seguir:

Microtarea uno. Se presentan imágenes de las leyendas utilizando un proyector multimedia y los estudiantes deben observar las imágenes y a partir únicamente del recurso visual deben inferir de qué tratan las leyendas y sus probables títulos.

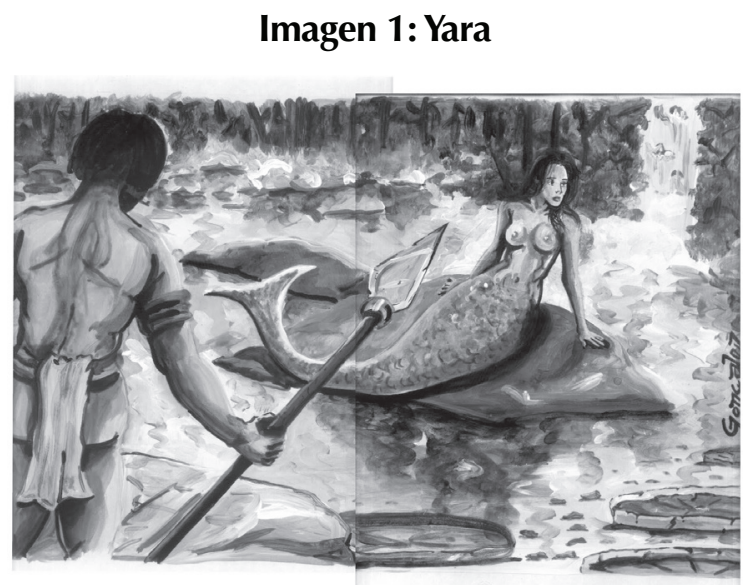

Fuente: Gonçalez, L. (2010). Aulas de Desenho. Yara [imagen]. Recuperado de http://desenhogoncalez.blogspot.com.br/2010/07/ aqui-outra-lenda-brasileira-iara-sereia.html

\section{Imagen 2: La Sayona}

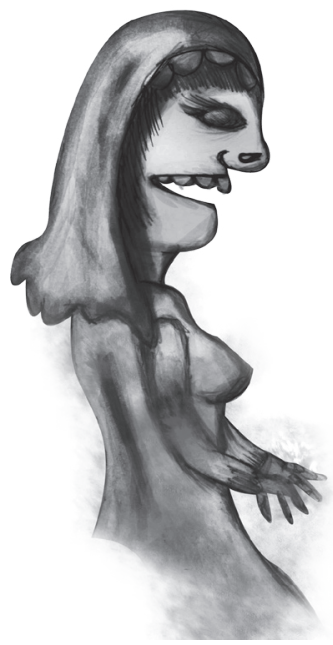

Fuente: La Sayona (2009). Mitos y Leyendas de Venezuela. La Sayona [imagen]. Recuperado de: http://mitosleyendasdevenezuela. blogspot.com.br.

Microtarea dos. Los participantes reciben las leyendas, hacen la lectura en conjunto y luego completan un cuadro, con información de los personajes leídos, sus características físicas y psicológicas, las semejanzas y diferencias entre ambas leyendas, así como la moraleja de cada una.

\section{Imagen 3: Hoja de trabajo para el tema de las leyendas}

\begin{tabular}{|c|c|c|}
\hline & \multicolumn{2}{|c|}{ Leyendas } \\
\hline & "La Sayona" & "lara" \\
\hline $\begin{array}{l}\text { - Personajes: } \\
\text { - Características } \\
\text { físicas y } \\
\text { psicológicas: }\end{array}$ & & \\
\hline Semejanzas: & & \\
\hline Diferencias: & & \\
\hline Moraleja: & & \\
\hline
\end{tabular}

Microtarea tres. Una vez que el grupo completa el cuadro anterior, se realiza una puesta en común sobre la información de la tarea anterior. Cada grupo tiene un representante que explica las respuestas del cuadro, y luego se inicia un debate sobre las respuestas y las observaciones hechas por los participantes. En este momento, todos pueden dar su opinión.

Tarea final. Esta tarea también es desarrolla en grupo. Se elige una de las leyendas estudiadas y 
se construye una nueva versión para la leyenda, la cual necesita ser presentada de una manera creativa a los demás.

\section{EL ENFOQUE POR TAREAS EN LA PRÁCTICA: APLICACIÓN DE LA PROPUESTA DIDÁCTICA}

Esta sección presenta el resultado de la aplicación de la propuesta didáctica efectuada con cuatro gru- pos de estudiantes del cuarto módulo del Curso de Letras -Español y Literatura Hispánica- del IFRR.

El desenvolvimiento de la propuesta se incluye en el cuadro siguiente, el cual incluye las microtareas aplicadas, las acciones desarrolladas mientras se aplicaban las tareas, el tiempo asignado para cada una y los resultados alcanzados:

Tabla 1

Análisis de la propuesta didáctica aplicada

\begin{tabular}{|c|c|c|c|}
\hline Microtareas & Acciones desarrolladas & Tiempo asignado & Resultados alcanzados \\
\hline $\begin{array}{l}\text { Microtarea } 1 \\
\text { Observe las imágenes siguientes } \\
\text { e intente identificar, mediante } \\
\text { las imágenes, de qué tratan las } \\
\text { leyendas y cuáles podrían ser } \\
\text { sus títulos. }\end{array}$ & $\begin{array}{l}\text { Primero se realizó una } \\
\text { introducción sobre el } \\
\text { concepto de leyendas, que } \\
\text { incluyó una indagación } \\
\text { sobre el conocimiento } \\
\text { que tenían los alumnos de } \\
\text { las leyendas brasileñas y } \\
\text { venezolanas estudiadas. } \\
\text { Luego, se les propuso a } \\
\text { los alumnos la primera } \\
\text { microtarea. }\end{array}$ & 30 minutos & $\begin{array}{l}\text { - Los estudiantes estaban } \\
\text { entusiasmados con el tema } \\
\text { tratado. } \\
\text { - La mayoría de los } \\
\text { estudiantes demostró } \\
\text { conocimiento superficial } \\
\text { sobre las leyendas, incluso } \\
\text { las brasileñas. } \\
\text { - Hubo una participación } \\
\text { efectiva en las respuestas de } \\
\text { los estudiantes. }\end{array}$ \\
\hline $\begin{array}{l}\text { Microtarea } 2 \\
\text { Los participantes reciben un } \\
\text { texto de las leyendas, hacen } \\
\text { la lectura en conjunto y } \\
\text { luego rellenan un cuadro, en } \\
\text { el cual anotan quiénes son } \\
\text { los personajes, cuáles son } \\
\text { sus características físicas y } \\
\text { psicológicas, las semejanzas y } \\
\text { diferencias entre las leyendas y } \\
\text { la moraleja de cada texto. }\end{array}$ & $\begin{array}{l}\text { Realización de la tarea } \\
\text { propuesta. }\end{array}$ & 30 minutos & $\begin{array}{l}\text { - Interacción en lengua } \\
\text { española. } \\
\text { - Organización y síntesis de } \\
\text { las ideas. } \\
\text { - Percepción de que las } \\
\text { leyendas pueden tener una } \\
\text { enseñanza moral, aplicable } \\
\text { a las experiencias cotidianas } \\
\text { de los estudiantes. }\end{array}$ \\
\hline $\begin{array}{l}\text { Microtarea } 3 \\
\text { Se da la puesta en común con } \\
\text { los datos obtenidos en la tarea } \\
\text { anterior. Se conversa sobre las } \\
\text { semejanzas y diferencias entre } \\
\text { las leyendas y sobre la moraleja } \\
\text { que pretenden ofrecer. }\end{array}$ & $\begin{array}{l}\text { En este momento, } \\
\text { fue seleccionado un } \\
\text { representante de cada } \\
\text { grupo que habló sobre } \\
\text { las respuestas del cuadro. } \\
\text { Luego, se estableció una } \\
\text { conversación a partir } \\
\text { de la puesta en común, } \\
\text { donde se pudo percibir } \\
\text { las perspectivas de cada } \\
\text { grupo sobre las leyendas } \\
\text { trabajadas. }\end{array}$ & 30 minutos & $\begin{array}{l}\text { - Se percibió que los } \\
\text { estudiantes hablaron de las } \\
\text { semejanzas y diferencias de } \\
\text { las leyendas con soltura. } \\
\text { - Fueron más allá de lo } \\
\text { que fue propuesto por el } \\
\text { profesor, pues hicieron } \\
\text { comparaciones con otras } \\
\text { leyendas y tomaron en } \\
\text { cuenta la cultura de los dos } \\
\text { países. }\end{array}$ \\
\hline
\end{tabular}




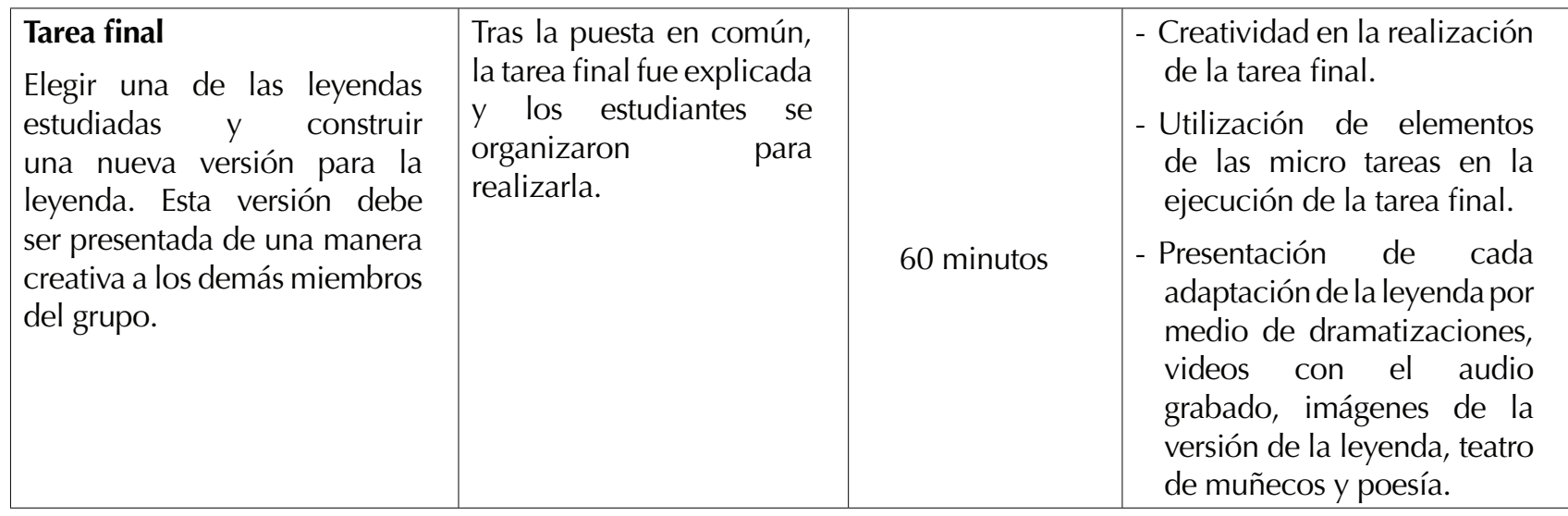

Fuente: Elaboración propia

\section{CONCLUSIONES}

El objetivo principal de este artículo se centra en plasmar una propuesta de desarrollo de actividades de español como lengua extranjera en un curso de formación de profesores, mediante el enfoque por tareas, teniendo por eje las leyendas de la frontera Brasil-Venezuela.

De este modo, se observa que el empleo del enfoque por tareas puede contribuir con el proceso de enseñanza-aprendizaje de español para los futuros profesores. Esto se debe a que este enfoque es una modalidad de enseñanza más centrada en el estudiante, pues según las observaciones hechas durante el experimento, permite atender las necesidades e interés de comunicación mediante la flexibilidad en la elección del camino para el desarrollo de los ejercicios propuestos, por el fomento de la cooperación y la participación de los miembros que componen los grupos de trabajo tanto en el aula como fuera de la escuela.

Siguiendo esa orden de ideas, se observa que el enfoque comunicativo en el aula de español como lengua extranjera puede ser considerado como una posibilidad para impartir temas como el medio natural, social y cultural, eligiendo para ese fin las leyendas pertenecientes al área fronteriza entre Brasil-Venezuela. Con esto, podría haber una mejor sistematización entre la formación del profesorado y las buenas prácticas de los métodos y enfoques de enseñanza de lenguas extranjeras en la enseñanza básica.
Para ejemplificar esa práctica, se han desarrollado unas tareas utilizando las leyendas indígenas de Brasil y Venezuela, tema que podrá ser llevado para el aula y que puede involucrar creación de textos orales y escritos, y demostrar así cómo se puede diseñar la secuencia de las distintas fases de las tareas.

Así, se pueden constatar las siguientes conclusiones que provienen del análisis del objetivo planteado:

Se logra validar el uso de la leyenda para enseñar español mediante el enfoque por tareas. Esto se logró con la argumentación en el apartado teórico, pues este tipo de textos sale del conocimiento del pueblo, además de mostrar la realidad cultural y social de los pueblos indígenas. La leyenda puede ofrecer situaciones comunicativas que involucran la observación, la escucha y la aprehensión de elementos contextuales (tales como relación entre personajes, espacio, tiempo y elemento), además de elementos pragmáticos, gestos, miradas y el estilo del narrador.

Dado que la comunicación es la principal función del lenguaje, usar el idioma para interactuar con el otro debe ser uno de los principales propósitos cuando se aprende una lengua, tomando en cuenta que la comunicación no es únicamente la enseñanza de las normas gramaticales y el aprendizaje del léxico, es también un proceso social. Así las cosas, el empleo de los recursos que ofrece la leyenda puede crear condiciones favorables para desarrollar la adquisición de la competencia comunicativa en los estudiantes.

Por otra parte, la motivación de los alumnos se favorece con el enfoque por tareas y la utilización de leyendas. Esto es relevante puesto que la 
motivación es un elemento importante para que se produzca el aprendizaje. Además del interés por trabajar con leyendas, también se genera motivación al trabajar en grupos, pues así se reúnen personas distintas y se desarrolla una tarea final. Esa práctica estrecha la relación entre los compañeros del aula, lo que produce una propuesta de trabajo muy positiva y enriquecedora.

Por lo que se ha observado y analizado, la práctica empleada como objeto de la investigación de la cual surge este artículo, puede desarrollar la competencia comunicativa y la adquisición de destrezas y habilidades lingüísticas. Así, se considera vital desarrollar este enfoque en la enseñanza de español como lengua extranjera, pudiendo aún utilizarlo en otras asignaturas relacionadas.

Este trabajo puede contribuir de manera significativa para el proceso de enseñanza-aprendizaje de los futuros profesores de español como lengua extranjera. Por ende, se podría poner en práctica presentado en su conjunto, y analizar su validez, llevando en consideración los aspectos que funcionan en otros contextos y cuáles se podrían mejorar en consonancia con la realidad de las escuelas de enseñanza básica.

\section{REFERENCIAS BIBLIOGRÁFICAS}

Cascudo. L. C. (2006). Literatura Oral do Brasil. São Paulo, Brasil: Global.

Chizzotti, A. (2003). A pesquisa qualitativa em ciências humanas e sociais: evolução e desafios. Revista Portuguesa de Educação. 16 (02), 221236. Recuperado de: http://www.unisc.br/portal/ upload/com_arquivo/1350495029.pdf.

Estaire, S. (2007). La enseñanza de lenguas mediante tareas: principios y planificación de unidades didácticas. Recuperado de: http://www.nebrija. es/espanolparainmigrantes/flash/ensenar/PDF/ articulo-tareas.pdf

Estaire, S. y Zanón, J. (1990). El diseño de unidades didácticas para la enseñanza de una segunda lengua. Comunicación, lenguaje y educación, 7-8, 55-90.

La Sayona (2009). Mitos y Leyendas de Venezuela. Recuperado de: http://mitosleyendasdevenezuela.blogspot.com.br.
López, S. F. y Blanco, A. N. (2011). Enfoque por tareas: Propuestas didácticas. Brasília, Brasil: Consejería de Educación de la Embajada de España.

McKernan, J. (1999). Investigación-acción y currículo. Madrid, España: Ediciones Morata, S.L.

Platero, A. M. y Ehrichs, V. P. (2011). Cuentos y Leyendas de la Amazonia brasileña. Colección OreIlana. Brasília, Brasil: Consejería de Educación de la Embajada de España.

Rodrigues, F. (2006). Migração Transfronteiriça na Venezuela. São Paulo, Brasil. Recuperado de: http://www.scielo.br/scielo.php?script=sci_arttext \&pid=S010340142006000200015\&lng=pt\&nrm $=$ iso\&tlng $=$ pt

Sánchez, A. P. (2009). La enseñanza de idiomas en los últimos cien años: métodos y enfoques. Madrid, España: Sociedad General Española de Librería, S. A.

Stenhouse, L. (1998). La investigación como base de la enseñanza. Madrid, España: Ediciones Morata, S.L.

Triviños, A. N. S (2012). Introdução à pesquisa em ciências sociais: a pesquisa qualitativa em educação. São Paulo, Brasil: Atlas. 